\title{
Effects of Fires in Juvenile Oil Palm Fields on Yield and Oil Palm Breeding
}

\author{
Claude Bakoumé (Corresponding author) \\ Sime Darby Technology Centre, 46050, Petaling Jaya, Malaysia \\ Tel: 601-73741884 E-mail: claude.bakoume@simedarby.com \\ Madi Galdima \\ La Dibamba Specialised Oil Palm Research Centre, P.O. Box 243 Douala, Cameroon \\ E-mail: madi.galdima@yahoo.fr \\ Sylvain Rafflegeau \\ CIRAD, UPR Systèmes de Pérennes, Montpellier, F-34398, France \\ E-mail: sylvain.rafflegeau@cirad.fr \\ Albert Flori \\ CIRAD, UPR Génétique Palmier, Montpellier, F-34398, France \\ E-mail: albert.flori@cirad.fr
}

Received: December 16, 2010 Accepted: December 31, 2010 doi:10.5539/jas.v3n3p225

\begin{abstract}
Fires in juvenile oil palm (Elaeis guinenesis Jacq.) fields cause the death and/or reduce the yield. The magnitude of the loss of yield in subsequent years has been assessed for the first time on four of the 25 progenies that composed the $20^{\text {th }}$ genetic trial laid out at La Dibamba (Cameroon) in 1993 which was accidentally victim of fires in 1996. Records of bunch production during the first five years of harvesting (1996-2000) showed that in the first two years after fires, total bunch weight was reduced by $35 \%$, bunch number by $26 \%$ and average bunch weight by $23 \%$. From two years after the fires onwards, burnt oil palms reacted by producing a high number of bunches, which compensated for the small average bunch weight. Fire damage to juvenile oil palms disrupted the selection of precocious progenies that helps procure for the plantations an early financial return on their investment.
\end{abstract}

Keywords: Oil palm, Fire, Yield reduction, Oil palm breeding, La Dibamba

\section{Introduction}

Africa, the continent of origin of oil palm, is, somewhat surprisingly, a net importer of palm oil although it possesses the most abundant natural palm groves. About 1 million hectares in the Continent are planted to oil palm, 50\% of which are smallholdings (Bakoumé et al., 2006). Africa's failure to be self-sufficient in oil palm production is revealed in the huge gap which exists between predicted yields of planting materials and yields actually obtained. This gap is at least partly explained by the smallholders' limited technical know-how concerning plantation establishment and management. In fact, Jalani et al. (2003) mentioned that good agricultural practices are necessary to allow planting materials to express their genetic potential and also to reduce the gap between yields obtained from smallholdings and those recorded by the industrial plantations. In Cameroon, estates whose agricultural practices are still relatively distant from the optimum for some of them have recorded yields of $2.8 \mathrm{t} / \mathrm{ha}$ of palm oil on average from 2006 to 2009 (Oil World, 2009) while yields of only around $1 \mathrm{t} /$ ha have been regarded as satisfactory by smallholdings where fertilizer applications were irregular or entirely absent, compounded by doubtful planting materials and very low performing local oil palm extraction facilities. However, to date, the best progenies yield around $5 \mathrm{t} /$ ha despite irregular and insufficient fertilizer applications (Bakoumé et al., 2010). Besides the limited management skills of smallholders, diseases and fires 
undoubtedly further contribute to reduction of yields. For example, Rafflegeau (2008) also listed fires among factors responsible for the low yields harvested by smallholders, usually called "village planters".

Of the diseases responsible for low yields, Fusarium wilt, caused by a soil-borne fungus Fusarium oxysporium f.s. elaeidis, is likely the most important in Africa. The disease either kills infected palms, reducing the number of standing oil palms per unit area, or enfeebles the plant. Weakened oil palms produce relatively small leaves and a small number of bunches with a low average bunch weight. Bunch yield reduction due to Fusarium wilt has been estimated at about 30\% in the western highlands of Cameroon (Ngoko et al., 2004).

Unlike the case of disease, whose impact is expressed in terms of proportion of harvest lost, the impact of fires is usually expressed in terms of the number of dead plants. Their impact is often simply estimated in terms of number of hectares affected. Such vague assessments of the impact of fires are usual in agriculture. In Côte d'Ivoire, statistics from the Ministry of Environment estimated that 33,000 hectares of cocoa and coffee were destroyed by fire between 1993 and 2003 (Zamble, 2007) but omitted to offer any figures estimating the corresponding yield losses.

In Southeast Asia, Root Cause Failure Analysis (RCFA) (2004) reported that more than 4 million hectares of cropped lands had been burnt in Southeast Asia between 1997 and 1998. RCFA concluded that the fires originated from human negligence or malevolence in many cases, as well as from agricultural pressure on forested lands and traditional agricultural practices. In Indonesia, for example, fires are known to be provoked by farmers during slash-and-burn land preparation for oil palm planting.

Fires are recurrent in smallholdings in Africa including Cameroon due to insufficient weed control compounded by the prolonged dry season of two to four months during which weeds dry out and increase the risk of fires. Bakoumé at al. (2006) reported that the pronounced dry season together with poor maintenance of planted plots resulted in the loss of parent oil palm materials from one or two plots yearly due to fire at the La Dibamba Oil Palm Research Station. The authors also noted that the fire had been caused by the slash-and-burn practices of the station's neighbours during land preparation for annual crops as well as the use of fire to flush out palm rats from their holes in oil palm plots. Bakoumé (1995) observed a decrease of the TBW and ABW in the 18th progeny trial planted at La Dibamba (Cameroon) in 1988 which had been the victim of fires in 1989, just one year after planting.

No assessment has yet been made of the impact of fire on yield of perennial crops, including oil palm. The fact that oil palms usually recover from burns suffered when the palms have reached or almost reached maturity may explain the limited interest in measuring the subsequent loss of yields. The current article envisages assessing the impact of fires in juvenile oil palm field on bunch yield. The consequences of incidence of fire for an oil palm breeding programme and a plantation are explored.

\section{Materials and methods}

This study was unplanned, as all studies of disasters should be. It was decided, rather, to seek out and analyze what data existed after accidental fires during a progeny trial. The oil palm plant material used consisted of 4 progenies out of 25 present in the $20^{\text {th }}$ progeny trial established at La Dibamba Oil Palm Research Station in Cameroon. Table 1 shows details of the progenies and the dura and pisifera parents crossed. La Dibamba is situated between $3^{\circ} 46^{\prime}$ and $4^{\circ} 01^{\prime} \mathrm{N}$ latitude and $9^{\circ} 44^{\prime}$ and $10^{\circ} 04^{\prime} \mathrm{E}$ longitude. The station's climatic, topographic and soil conditions are suitable for oil palm development and production (Bakoumé \& Mahbob, 2005). The station experiences 3.5 months of marked dry season from December to the middle of March. The statistical design of the progeny trial was a $5 \times 5$ balanced lattice with 6 replicates and 12 palms per elementary plot (72 palms per progeny). The planting was laid out on a $9 \mathrm{~m}$ equilateral triangular, giving $143 \mathrm{palms} / \mathrm{ha}$. The progeny trial was laid out in 1993 and was victim of fire in March 1996, which is three years after planting and the first year of fruit bunch production. Figure 1 shows the area of the trial that was affected by the fire.

$<$ Table 1>

$<$ Figure 1>

The 4 progenies selected for the current study comprised progeny LM 16896 with the maximum number of palms burnt (48 out of 72 planted), LM 17078, LM 17067, and the control LM 17144 with moderate numbers of palms burnt ( 23 out of 72 planted, 26 out of 72 planted, and 25 out of 72 planted, respectively). The numbers of palms burnt per replicate of the original trial and per progeny selected are detailed in Table 2.

$<$ Table 2>

The status of each tree in the burnt area was recorded after the fire and classified into: 
- Unburnt: oil palm with zero leave burnt

- Partially burnt: oil palm with part or all the open leaves burnt except the unopened spear

- Totally burnt: oil palm with all the leaves burnt including the unopened spear

The parameters measured for the whole trial (25 progenies) on a per individual oil palm tree basis from 1996 to 2000 were bunch number $(\mathrm{BN})$ and the total bunch weight (TBW). The average bunch weight (ABW) was calculated from TBW and BN.

Graphs were constructed for a better visualization of TBW, BN and ABW evolutions from 1996 to 2000. Analysis of variance (ANOVA) was performed using the MIXED procedure of SAS software (SAS Institute 1996) for BN, ABW and TBW to search for differences among the three classes of palms as classified according to the degree of leaves' burns, in addition to the progeny and replication effects. A random plot effect was added to the model to take into account spatial dependency between palms. The following linear model was used for the bunch yield components:

$$
Y_{i j k l}=m+a_{i}+b_{j}+c_{k}+p_{i j}+e_{i j k l}
$$

Where:

$\mathrm{Y}_{\mathrm{ijkl}}=$ production of $\mathrm{t}^{\text {th }}$ oil palm with $\mathrm{k}^{\text {th }}$ degree of burns

$a_{i}=$ effect of $i^{\text {th }}$ progeny

$b_{j}=$ effect of $j^{\text {th }}$ replicate

$c_{k}=$ effect of $k^{\text {th }}$ degree of burns

$\mathrm{p}_{\mathrm{ij}}=$ effect of elementary plot

$\mathrm{e}_{\mathrm{ijkl}}=$ Residual error.

Subsequently, Turkey's HSD test was used to compare mean values of BN, ABW and TBW over years and over the young period of trees, the young period being the period of three to five years after planting. The young period is particularly significant in its use to determine progeny precocity, which is determined by observing the TBW from 3-to-5-year-old oil palms. Precocity, or early good performance of a progeny, indicates an early financial return on the investment for the plantation (Bakoumé, 2007). A precocious progeny is a progeny whose TBW represents at least $112 \%$ that of the control (LM2T x DA5D) progeny, the highest yielding progeny of the $1^{\text {st }}$ cycle of reciprocal recurrent selection (RRS).

\section{Results and discussion}

In 1996, the year of the fires, and in 1997, the year after them, the bunch yield (total bunch weight; TBW) and its components (BN and ABW) were high, in absolute terms, for the unburnt palms. During this period, the TBW of partially burnt palms and totally burnt palms represented $58-79 \%$ and $40-82 \%$ of that of the unburnt palms, respectively (Figure 2).

$<$ Figure 2>

From the second year after the fires onwards, the TBW leveled up for the three classes of palms due to increased bunch numbers. The low values of TBW observed were explained by both the low BN and the reduced ABW. The BN for partially burnt palms and for totally burnt palms represented $76 \%$ and $72 \%$, respectively, of the BN of unburnt palms (Figure 3). Meanwhile, ABW also registered 19\% and $27 \%$ reduction in partially burnt palms and in totally burnt palms, respectively, for the same period (Figure 4).

$<$ Figure 3>

$<$ Figure $4>$

ANOVA revealed significant differences among the three classes of palms, confirming the effect of fires on bunch yield and its components (Table 3). The Turkey's (HSD) test showed a clear separation of mean values of $\mathrm{BN}, \mathrm{ABW}$ and TBW between unburnt palms on the one hand and partially burnt and totally burnt palms on the other hand, both in the year the fires happened as well as in the following year. From the second year after the fires onwards, however, the TBW of the partially burnt and totally burnt palms caught up to that of the unburnt palms despite the low values of ABW, with the exception of the last year of observation (2000). The improvement in TBW for partially burnt and totally burnt palms derived from significant increments in BN, which compensated for the low ABW. The BN confirms its position as the predominant factor contributing to TBW and subsequently to oil yield, as earlier reported by Lubis et al. (1991). It is believed that the yield 
reduction and the reaction of the oil palm tree might have depended on whether fire burns were limited to a few leaves or extended to all the leaves except the spear or to all the leaves including the spear.

By producing a high number of small bunches after burns, the oil palm can be better likened to an r-strategist, or $\mathrm{r}$ species, which shows high fecundity or ability to reproduce offspring even with small body size and under unstable or unpredictable environments, rather than to a $\mathrm{K}$-strategist, or $\mathrm{K}$ species, which produces fewer offspring with large body size when it is subjected to marginal environmental conditions (Piaka, 1970). Fires have been shown to have affected the TBW during the first 4 years of harvest, reducing the ABW up to the $7^{\text {th }}$ year after fires for some of the progenies when fires occurred one year after planting (Bakoumé, 1995). The duration of the impact of fire on bunch yield and its components was observed to depend on the age of the victimised oil palms.

The bunch yield and bunch number were affected by fires $(P=0.0001)$ during the young period $(1996-1998)$. The total bunch weight from the unburnt palms was higher than those from the partially burnt and totally burnt palms. During the young period (1996-1998) the mean annual bunch yield in unburnt palms was $11.17 \mathrm{t} / \mathrm{ha}$. Based on an oil extraction rate for young palm estimated at $15 \%$ (allowing for the high water content of the mesocarp) and on the current price for crude palm oil (CPO) of USD848.561 per tonne, the annual income expected from the sale of crude palm oil corresponds to USD1422 per hectare. The annual loss in income is calculated to be around $14 \%$ and $17 \%$ for lowered yield in partially burnt palms and totally burnt palms, respectively.

\section{Conclusion}

Finally, the $20^{\text {th }}$ progeny trial laid at La Dibamba Oil Palm Research Centre in 1993, which was accidentally burnt by fires 3 years after planting, when oil palms started producing fruit bunches for the first time, showed a significant reduction of TBW in partially burnt and totally burnt palms due to a low number of small bunches harvested the year when the fires happened and also in the following year. The number of bunches increased from the second year onwards and resulted in leveling of TBW over unburnt, partially burnt and totally burnt palms despite the fact that the ABW did not improve much. Accidental burning of juvenile oil palms is detrimental to the search of oil palm breeders for precocious progenies and to the expectations of plantations for early financial return on their investment. This study has shown the importance of preventing fires among oil palms at all ages. Some fire prevention measures may include the weeding of wide circles around oil palms, establishment of a fire screen around the oil palm field at the beginning of the dry season, and mostly increasing awareness among the public and smallholders of the effects of fires on the post-fire survival and bunch yield of oil palm.

\section{References}

Bakoumé, C. (2007). Breeding for oil yield and short palms in Cameroon. Palmas, 28, 77-83.

Bakoumé, C. (1995). Analyse et exploitation des essais génétiques palmiers à huile de La Dibamba [Analysis and exploitation of La Dibamba's oil palm genetic trials]. Report, Centre de Cooperation Internationale en Recherche Agronomique pour le Developpement, Montpellier, France.

Bakoumé, C., Louise, C. \& Tengoua, F. F. (2006). Qualitative and quantitative evolution of selected oil palm seed production at la Dibamba Specialised Centre on Oil Palm Research (Cameroon). The Planter, 82, 517-530.

Bakoumé, C., Madi Galdima \& Tengoua, F. F. (2010). Experimental modification of reciprocal recurrent selection in oil palm breeding in Cameroon. Euphytica, 171, 235-240. doi:10.1007/s10681-009-0034-1, http://dx.doi.org/10.1007/s10681-009-0034-1

Bakoumé, C. \& Mahbob Bin Abdullah. (2005). Potentiality of the oil palm industry in Cameroon. The Planter, 81, 483-491.

Jalani, B. S., Chan, K. W. \& Rajanaidu, N. (2003). Contributions of breeding and agronomy in increasing oil palm yield. Paper presented at ISOPB seminar on The Progress of Oil Palm Breeding and Selection. 6-9 October 2003, Medan, Indonesia.

Lubis , R. A., Akiyat, B. N. \& Nouy, N. (1991). Comparison of the yield of first cycle DxP crosses of the Marihat RCEC in North Sumatra. In: PORIM (Ed) Proceedings of PORIM International Oil Palm Conference on Progress, Prospects and Challenges towards the 21st Century (pp. 226-231), Kuala Lumpur, Malaysia.

Ngoko, Z. Bakoume, C., Djoukeng, V., Tchamo, P., Imele, B., Adon, N. (2004). Factors Affecting Oil Palm Smallholders' Oil Palm Production in the Western Highlands of Cameroon the Planter, 80, 299-306.

Oil World. (2009). Oil World Annual. ISTA - Mielke. 1-21. 
Piaka, E. R. (1970). On r and K selection. American Naturalist, 104, 592-597. doi:10.1086/282697, http://dx.doi.org/10.1086/282697

Rafflegeau, S. (2008). Dynamique d'implantation et conduite technique des plantations villageoises de palmier à huile au Cameroun : facteurs limitants et raisons des pratiques [Dynamics in the technical lay-out and running of villager's oil palm plantations in Cameroon: Limiting factors and practices'ground]. $\mathrm{PhD}$ thesis, Paris Institute of Technology for Life, Food and Environmental Sciences Technology, Paris, France.

SAS Institute. (1996). SAS procedures guide. Release 6.12 SAS Institute (Ed.).

RCFA. (2004). Projet d'application du système d'évaluation des risques d'incendie à l'Asie du Sud-est. Réseau des conseillers forestiers de l'ACDI [Implementation system project of fire risks assessment in South-East Asia. ACDI forest advisers' network]. [Online] Available: http://www.rcfa-cfar.org/french/f.profile.18.htm. (May 30, 2007).

Zamble, F. (2007). Les feux de brousses emportent forets et cultures [Bush fires sweep forets and crops]. Inter Press New Agency. [Online] Available: http://www.ipsinternational.org/fr/note.asp?idnews=3533 (May 30, 2007).

Table 1. Progenies and parental crosses of the $20^{\text {th }}$ progeny trial at La Dibamba

\begin{tabular}{|c|c|c|c|c|c|}
\hline \multirow{2}{*}{$\begin{array}{l}\text { Progeny number in the } \\
\text { trial }\end{array}$} & \multirow[t]{2}{*}{ Progeny } & \multicolumn{2}{|c|}{ Parental crosses } & \multirow{2}{*}{$\begin{array}{l}\text { Origin } \\
\text { Dura }\end{array}$} & \multirow[b]{2}{*}{ Pisifera/tenera } \\
\hline & & Dura & Pisiferaltenera & & \\
\hline 1 & LM $17144^{* \circ}$ & DA 10D & \begin{tabular}{|l|l|}
$\mathrm{x}$ & LM 2T \\
\end{tabular} & Dabou & Brt10 \\
\hline 2 & LM 17046 & LM 9067D & \begin{tabular}{|l|l|}
$\mathrm{X}$ & LM 5336P \\
\end{tabular} & DA5D x DA3D & LM2T x LM5T \\
\hline 3 & LM 16891 & LM 90260D & \begin{tabular}{|l|l|}
$x$ & LM 5335P \\
\end{tabular} & DA5D $\times$ DA3D & LM2T x LM5T \\
\hline 4 & LM 16891 & LM 90260D & \begin{tabular}{|l|l|}
$x$ & LM 5335P \\
\end{tabular} & DA5D x DA3D & LM2T x LM5T \\
\hline 5 & LM 17076 & LM 7813D & $\begin{array}{ll}\mathrm{X} & \text { LM 5336P } \\
\end{array}$ & DA5D $\times$ DA3D & LM2T x LM5T \\
\hline 6 & LM 17141 & LM 7409D & \begin{tabular}{|l|l|}
$\mathrm{X}$ & LM 5336P \\
\end{tabular} & DA5D $\times$ DA3D & LM2T x LM5T \\
\hline 7 & LM $16896^{\circ}$ & LM 7422D & $\begin{array}{ll}\mathrm{x} & \text { LM 5337P } \\
\end{array}$ & DA5D x DA3D & LM2T x LM5T \\
\hline 8 & LM 17171 & LM 8800D & \begin{tabular}{|l|l|}
$\mathrm{x}$ & $\mathrm{PO} 4234 \mathrm{~T}$ \\
\end{tabular} & DA5D x DA3D & LM13T x LM9T \\
\hline 9 & LM 17133 & LM 10328D & \begin{tabular}{|l|l|}
$\mathrm{x}$ & $\mathrm{PO} 3848 \mathrm{P}$ \\
\end{tabular} & DA5D x DA3D & LM13T x LM9T \\
\hline 10 & LM 17172 & LM 10304D & $\mathrm{x}$ PO 4232T & DA5D x DA3D & LM13T x LM9T \\
\hline 11 & LM 16890 & LM 9026D & $\mathrm{x}$ PO 4234T & DA5D x DA3D & LM13T x LM9T \\
\hline 12 & LM 16895 & LM 9079D & \begin{tabular}{|l|l|}
$\mathrm{x}$ & LM 6518T \\
\end{tabular} & DA5D x DA3D & LM13T x LM9T \\
\hline 13 & LM 17139 & LM 9042D & \begin{tabular}{|l|l|}
$x$ & PO 4233T \\
\end{tabular} & DA5D x DA3D & LM13T x LM9T \\
\hline 14 & LM 16826 & LM 7422D & $\mathrm{x}$ PO 4233T & DA5D x DA3D & LM13T x LM9T \\
\hline 15 & LM 17140 & LM 7409D & $\mathrm{x}$ PO 3649P & DA5D x DA3D & LM13T x LM9T \\
\hline 16 & LM 17170 & LM 8800D & \begin{tabular}{|l|l}
$x$ & LM 10670T \\
\end{tabular} & DA5D x DA3D & LM2T x LM9T \\
\hline 17 & LM 17132 & LM 10328D & \begin{tabular}{|l|l|}
$x$ & LM 10669T \\
\end{tabular} & DA5D x DA3D & LM2T x LM9T \\
\hline 18 & LM 17165 & LM 9865D & \begin{tabular}{|l|l|}
$\mathrm{x}$ & $\mathrm{LM} 10670 \mathrm{~T}$ \\
\end{tabular} & DA5D $x$ DA3D & LM2T x LM9T \\
\hline 19 & LM 17173 & LM 9865D & \begin{tabular}{|l|l|}
$\mathrm{x}$ & LM 10672T \\
\end{tabular} & DA5D x DA3D & LM2T x LM9T \\
\hline 20 & LM $17067^{\circ}$ & LM 9022D & \begin{tabular}{|l|l|}
$\mathrm{x}$ & LM 10669T \\
\end{tabular} & DA5D x DA3D & LM2T x LM9T \\
\hline 21 & LM 17033 & LM 9079D & \begin{tabular}{|l|l|}
$\mathrm{x}$ & $\mathrm{PO}$ 4230P \\
\end{tabular} & DA5D $x$ DA3D & LM2T x LM9T \\
\hline 22 & LM 17034 & LM 9022D & $\mathrm{x} \quad \mathrm{PO} 4230 \mathrm{P}$ & DA5D x DA3D & LM2T x LM9T \\
\hline 23 & LM 17116 & LM 7409D & \begin{tabular}{|l|l|}
$\mathrm{x}$ & $\mathrm{PO} 4230 \mathrm{P}$ \\
\end{tabular} & DA5D x DA3D & LM2T x LM9T \\
\hline 24 & LM $17078^{\circ}$ & LM 7409D & \begin{tabular}{|l|l|}
$\mathrm{x}$ & LM 10670T \\
\end{tabular} & DA5D $x$ DA3D & LM2T x LM9T \\
\hline 25 & LM 17096 & LM 7813D & \begin{tabular}{|l|l|}
$\mathrm{x}$ & LM 10669T \\
\end{tabular} & DA5D $x$ DA3D & LM2T x LM9T \\
\hline
\end{tabular}

D: dura palm, T: tenera palm, P: pisifera palm, DA: Dabou (Côte d'Ivoire), LM: La Mé (Côte d'Ivoire), PO: Pobè (Benin) LM2T: second genitor of tenera type selected at La Mé, LM 1744: $1744^{\text {th }}$ progeny obtained at La Mé, *: control, ${ }^{\circ}$ : progenies used to study the effect of fires are highlighted 
Table 2. Number of palms burnt per progeny and per replicate (or elementary plot)

\begin{tabular}{|c|c|c|c|c|c|c|c|c|}
\hline \multirow[t]{2}{*}{ Progeny } & \multicolumn{6}{|c|}{ Replicate } & \multirow[t]{2}{*}{ Total } & \multirow{2}{*}{$\begin{array}{c}\text { Percentage } \\
(\%)\end{array}$} \\
\hline & I & II & III & VI & IV & V & & \\
\hline LM17144 & 0 & 0 & 0 & 2 & 12 & 11 & 25 & 35 \\
\hline LM16896 & 0 & 0 & 12 & 12 & 12 & 12 & 48 & 67 \\
\hline LM17067 & 0 & 0 & 4 & 10 & 0 & 12 & 26 & 36 \\
\hline LM17078 & 0 & 0 & 0 & 4 & 12 & 7 & 23 & 32 \\
\hline
\end{tabular}

Table 3. Probability of existence of fire effect and comparison of mean values of bunch yield and its components

\begin{tabular}{|l|c|c|c|c|c|c|}
\hline & TBW_1996 & TBW_1997 & TBW_1998 & TBW_1999 & TBW_2000 & TBW_96-98 \\
\hline $\begin{array}{l}\text { Probability P of F computed }> \\
\text { Tabular F for class effect }\end{array}$ & 0.0000 & 0.0044 & 0.9580 & 0.9490 & 0.1058 & 0.0001 \\
\hline Unburnt palms & $56.62 \mathrm{a}$ & $68.88 \mathrm{a}$ & 123.44 & 148.80 & 146.23 & $82.73 \mathrm{a}$ \\
\hline Partially burnt palms & $32.95 \mathrm{~b}$ & $54.48 \mathrm{~b}$ & 123.99 & 150.12 & 154.09 & $70.86 \mathrm{~b}$ \\
\hline Totally burnt palms & $22.93 \mathrm{~b}$ & $56.34 \mathrm{ab}$ & 126.24 & 151.04 & 141.38 & $69.06 \mathrm{~b}$ \\
\hline \hline & BN_1996 & BN_1997 & BN_1998 & BN_1999 & BN_2000 & BN_96-98 \\
\hline $\begin{array}{l}\text { Probability P of F computed }> \\
\text { Tabular F for class effect }\end{array}$ & 0.0000 & 0.0269 & 0.0236 & 0.0002 & 0.0050 & 0.0001 \\
\hline Unburnt plots & $14.50 \mathrm{a}$ & $12.47 \mathrm{a}$ & $14.97 \mathrm{~b}$ & $14.23 \mathrm{~b}$ & $11.91 \mathrm{~b}$ & $13.96 \mathrm{a}$ \\
\hline Partially burnt palms & $9.93 \mathrm{~b}$ & $10.44 \mathrm{~b}$ & $16.72 \mathrm{a}$ & $15.88 \mathrm{a}$ & $13.12 \mathrm{a}$ & $12.39 \mathrm{~b}$ \\
\hline Totally burnt palms & $6.92 \mathrm{~b}$ & $12.13 \mathrm{ab}$ & $17.12 \mathrm{a}$ & $16.85 \mathrm{a}$ & $12.11 \mathrm{ab}$ & $12.07 \mathrm{~b}$ \\
\hline \hline & ABW_1996 & ABW_1997 & ABW_1998 & ABW_1999 & ABW_2000 & ABW_96-98 \\
\hline $\begin{array}{l}\text { Probability P of F computed }> \\
\text { Tabular F for class effect }\end{array}$ & 0.0000 & 0.0067 & 0.0377 & 0.0001 & 0.0954 & 0.3810 \\
\hline Unburnt palms & $3.67 \mathrm{a}$ & $5.65 \mathrm{a}$ & $8.22 \mathrm{a}$ & $10.63 \mathrm{a}$ & 12.63 & 5.99 \\
\hline Partially burnt palms & $2.67 \mathrm{~b}$ & $5.03 \mathrm{~b}$ & $7.72 \mathrm{a}$ & $9.77 \mathrm{~b}$ & 12.11 & 5.80 \\
\hline Totally burnt palms & $4.76 \mathrm{~b}$ & $7.43 \mathrm{a}$ & $9.09 \mathrm{~b}$ & 11.70 & 5.69 \\
\hline
\end{tabular}



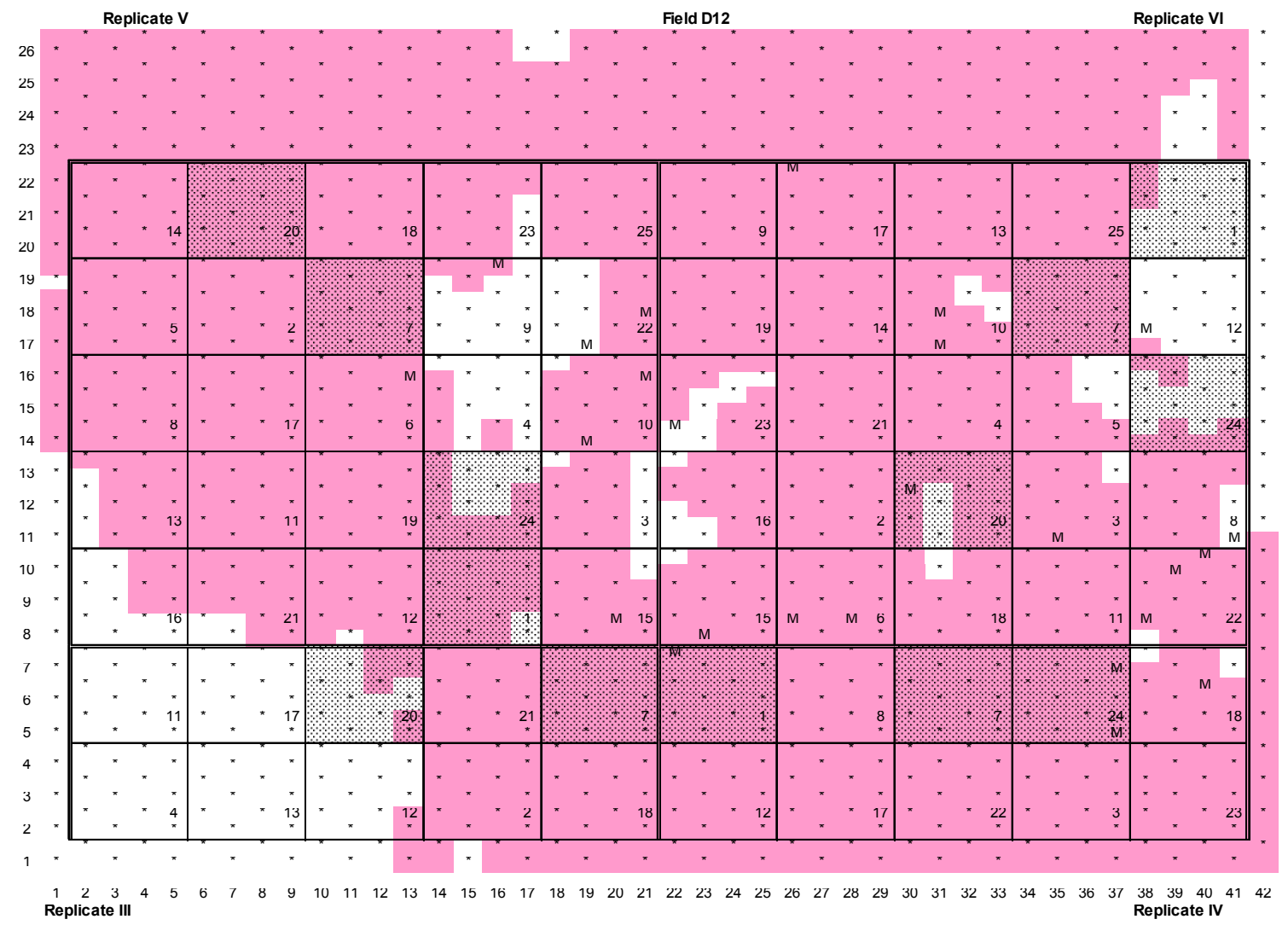

Field D02

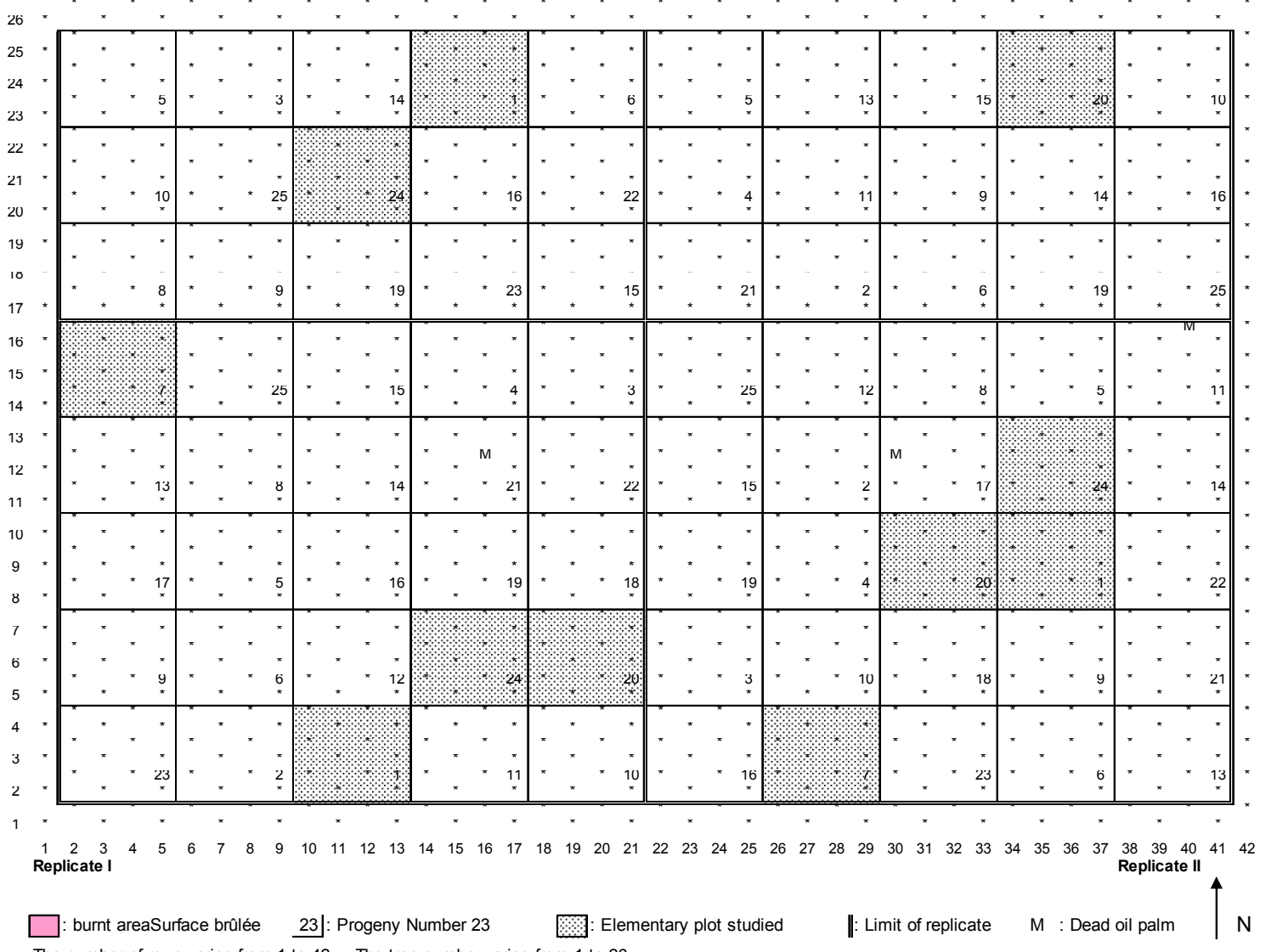
The number of rows varies from 1 to 42 The tree number varies from 1 to 26

Figure 1. Fire coverage of the $20^{\text {th }}$ progeny trial laid out at La Dibamba 


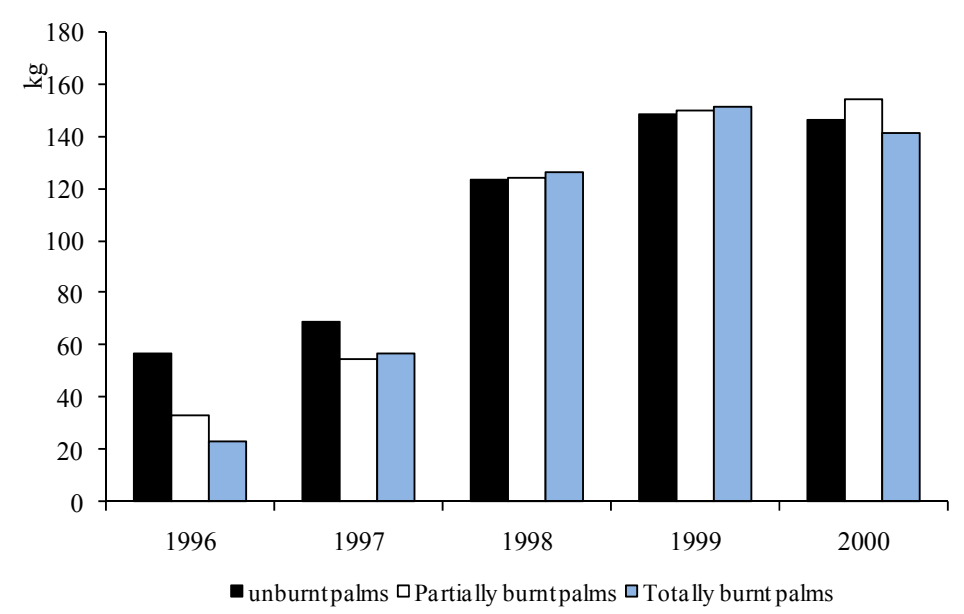

Figure 2. Annual evolution of total bunch weight

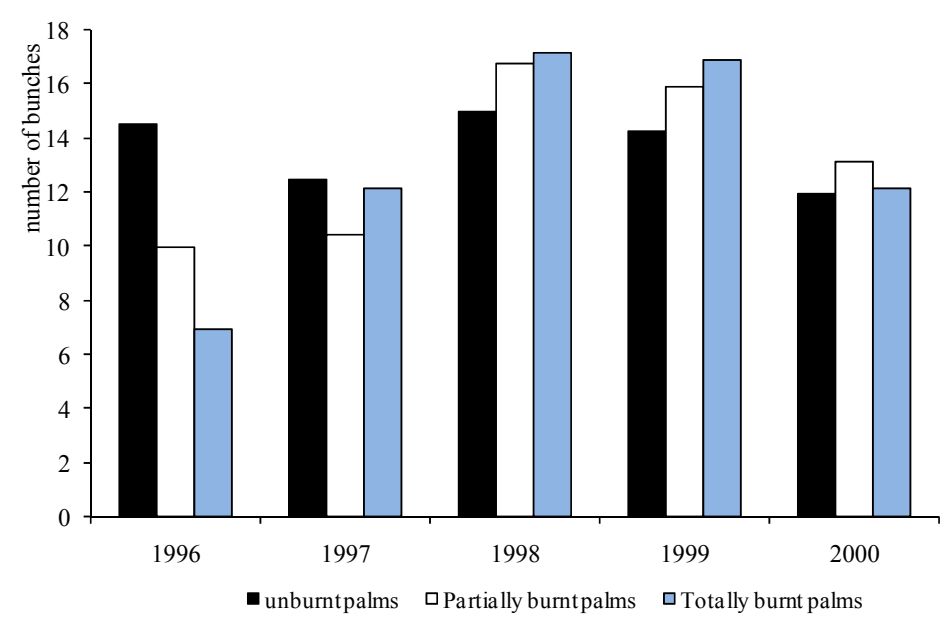

Figure 3. Annual bunch numbers between 1996 and 2000

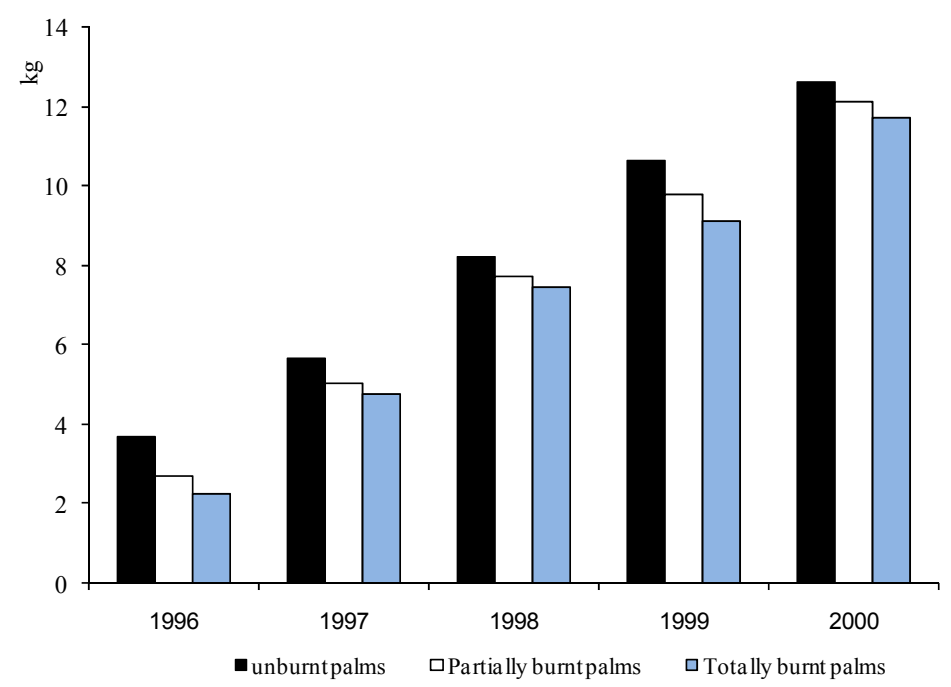

Figure 4. Average bunch weights during the observation period 